\title{
The impact of implementation of the Breastfeeding Friendly Primary Care Initiative on the prevalence rates of breastfeeding and causes of consultations at a basic healthcare center
}

\author{
Letícia O. Cardoso, ${ }^{1}$ Alessandra S. T. Vicente, ${ }^{2}$ \\ Jorginete J. Damião, ${ }^{3}$ Rosane V. V. F. Rito ${ }^{4}$
}

\begin{abstract}
Objective: To compare the prevalence rates of breastfeeding and the principal causes of consultations at the infant and neonatal clinic of a basic healthcare center in the city of Rio de Janeiro, before and after its being accredited by the Breastfeeding Friendly Primary Care Initiative.

Methods: Information was analyzed from 121 and 200 children followed-up at the healthcare center before and after certification, respectively. Type of feeding was classified as exclusive breastfeeding, predominant breastfeeding or breastfeeding, and the 10th International Classification of Diseases was used to classify the complaints causing consultations.

Results: A statistically significant increase was observed in the prevalence of exclusive breastfeeding, both among those less than 4 months old ( 68 vs. $88 \% ; p<0.0001$ ) and among children aged from 4 to 6 months ( 41 vs. $82 \% ; p<$ $0.0001)$. Furthermore, an impressive increase was observed in the prevalence of breastfeeding in children more than 6 months old, especially those aged 9 to 12 months ( $24 \mathrm{vs.} 82 \%$; < 0.0001 ). After certification, there was also a reduction in the number of consultations motivated by some type of disease among infants more than 4 months old.

Conclusion: Implementation of the Breastfeeding Friendly Primary Care Initiative proved to be an important strategy for increasing the rate of breastfeeding and reducing consultations due to disease among infants less than one year old cared for at this health center.
\end{abstract}

J Pediatr (Rio J). 2008;84(2):147-153: Breastfeeding, primary healthcare, child health, public health.

\section{Introduction}

Breastfeeding is one of the principal practices that promotes health, and is associated with the reduction of infant morbidity and mortality, with positive repercussions throughout life. ${ }^{1-5}$ Despite breastfeeding promotion being one of the targets of public policy in Brazil, the prevalence of breastfeeding (BF) has not yet reached the level recommended by the World Health Organization (WHO), which is that BF be the exclusive form of feeding up until 6 months, and be continued, together with complementary foods until 2 years or more. $^{6}$

Although $71 \%$ of Brazilian children start breastfeeding on the first day of their lives, weaning is started early. ${ }^{7}$ Nevertheless, studies undertaken during the last 30 years in Brazil demonstrate that the median BF duration has increased from 2.5 months in 1975 to 9.9 months in 1999 , demonstrating that

1. Doutoranda em Saúde Pública, Instituto Fernandes Figueira, Fundação Oswaldo Cruz (Fiocruz), Rio de Janeiro, RJ, Brazil.

2. Pós-graduanda em Nutrição Clínica, Universidade Gama Filho, Rio de Janeiro, RJ, Brazil.

3. Mestre, Fiocruz, Rio de Janeiro, RJ, Brazil.

4. Doutoranda em Saúde da Criança e da Mulher, Fiocruz, Rio de Janeiro, RJ, Brazil.

No conflicts of interest declared concerning the publication of this article.

Suggested citation: Cardoso LO, Vicente AS, Damião JJ, Rito RV. The impact of implementation of the Breastfeeding Friendly Primary Care Initiative on the prevalence rates of breastfeeding and causes of consultations at a basic healthcare center. J Pediatr (Rio J). 2008;84(2):147-153.

Manuscript received Oct 22 2007, accepted for publication Jan 212008.

doi:10.2223/JPED.1774 
the practice has recovered on a national level. Furthermore, increases have been observed in the rate of exclusive BF (EBF) among infants under 4 months old, which has increased from $3.6 \%$ in 1986 to $35.6 \%$ in $1999 .{ }^{8}$ Recent studies conducted in certain Brazilian cities, such as Botucatu and Rio de Janeiro, have also identified increases in the practice of EBF among children less than 6 months old and of BF during the first year of life. ${ }^{9,10}$

In the state of Rio de Janeiro, one of the most recent strategies adopted as part of the BF promotion policy is a Breastfeeding Friendly Primary Care Initiative (BFPCI). The objective of this initiative is the promotion protection and support of BF, by means of mobilizing the state's basic healthcare centers (BHC) to adopt the "Ten Steps to Successful Breastfeeding in Primary Care". In addition to this, the initiative also includes an important role in supporting families, through the $\mathrm{BHC}$ in partnership with the hospitals, which should help to make BF a universal practice, thereby contributing to the health and wellbeing of babies and their mothers. ${ }^{11}$

The objective of this study is to compare the prevalence rates of $\mathrm{BF}$ and the principal causes of consultations at the infant and neonatal clinic at a $\mathrm{BHC}$ belonging to the municipal healthcare system of the city of Rio de Janeiro, before and after certification on the BFPCI, with the intention of investigating the impact of the initiative on these outcomes.

\section{Methods}

The BHC investigated in this study is in the East quarter of the city of Rio de Janeiro and is responsible for the care of, on average, 380 children under the age of one year each month, at its infant and neonatal clinic. This was the first unit in the city to be awarded the BFPCI accreditation, in May of 2003, after a period of interventions and assessments starting in 2001 . This process has since been formalized by the regulations contained in resolution SES 2673, passed on 2nd March, 2005 by the Rio de Janeiro state health department. ${ }^{12}$ The initiative was designed on the basis of the results of a systematic review of studies published on infant nutrition, between 1980 and 1999, carried out to identify strategies and procedures appropriate to a primary healthcare system that effectively increase the duration of $\mathrm{BF}^{13}$ This review made it possible to propose the "Ten Steps to Successful Breastfeeding in Primary Care", which specify items ranging from the creation of a written standard, capacitation and training of all professionals at the $\mathrm{BHC}$ to welcoming, taking seriously and dealing with doubts and concerns expressed by expectant mothers and their families about the practice of breastfeeding.

In order to verify the impact of the initiative, two cohorts of children less than 1 year old were studied. All of these children had been followed-up at the infant and neonatal clinic of the BHC, one group between May of 2001 and May of 2002 and the other from May of 2003 to May of 2004. The first period ended one year before the date of BFPCI certification and was chosen in order to avoid influence on the outcomes under analysis from the fact that, from May 2002 onwards, training of the healthcare team was intensified during the buildup to certification. The second period started soon after the BHC received its accreditation.

The study enrolled every child seen at the BHC at least once, in each age group of interest (described below).

Data were obtained from the medical records of children eligible for enrollment, and this information was recorded by the second author of this paper, using a form designed for the purpose. The following information was collected: date of birth, dates of consultations, age of mother, reason for consultation and type of feeding at the time of the consultation.

The infants were classified by age as belonging to one of the following groups: 0 to $3.9 ; 4$ to $5.9 ; 6$ to 8.9 or 9 to 12 months. Mothers were classified by age into the following groups: $\leq 19$ years, from 20 to 34 years and $\geq 35$ years. Type of feeding was classified in accordance with WHO definitions ${ }^{14}$ :

- EBF: children fed exclusively breastmilk, with no water, teas, juices, other types of milk or other foods;

- predominant BF (PBF): children fed breastmilk plus water and/or tea and/or juices, but no other types of milk or food;

- BF: children fed breastmilk irrespective of any other type of food.

It should be pointed out that the health professionals at this $\mathrm{BHC}$ had all received previous training on the value of recording the type of feeding for each child regularly and on how to do so correctly according to the standardized categories presented above, thereby making it possible to use this variable with a relative degree of confidence.

The health-related outcomes that motivated each consultation were classified according to the International Classification of Diseases (ICD-10), ${ }^{15}$ which was employed by the municipal healthcare system of Rio de Janeiro at the time the study was conducted. This classification resulted in the following categories: routine consultation (asymptomatic); diarrhea; respiratory infections (RI) and others.

Epi-Info $6.04^{16}$ was used for data entry and analysis. The results from before BFPCI accreditation were compared with the results from after accreditation. The chi squared test was used to compare proportions and differences were defined as statistically significant where $p<0.05$.

This study was submitted to the Research Ethics Committee of the Rio de Janeiro Municipal Health Department (Secretaria Municipal de Health) and all procedures were approved with no restrictions.

\section{Results}

After application of the inclusion criteria, a total of 121 medical records from before certification and 200 medical 
Table 1 - Distribution of the study population by sex of child and age of mother, before and after BFPCI certification of a BHC in the city of Rio de Janeiro

\begin{tabular}{|c|c|c|c|c|c|}
\hline \multirow[b]{2}{*}{ Variables } & \multicolumn{2}{|c|}{ Pre-BFPCI } & \multicolumn{2}{|c|}{ Post-BFPCI } & \multirow[b]{2}{*}{$\mathbf{p}$} \\
\hline & $\mathbf{n}$ & $\%$ & $\mathbf{n}$ & $\%$ & \\
\hline \multicolumn{6}{|l|}{ Sex of child } \\
\hline Female & 63 & 52.1 & 98 & 49.0 & \\
\hline Male & 58 & 47.9 & 102 & 51.0 & 0.59 \\
\hline \multicolumn{6}{|c|}{ Mother's age (years) } \\
\hline$\leq 19$ & 11 & 16.9 & 35 & 23.5 & \\
\hline 20 to 34 & 49 & 75.4 & 98 & 65.8 & \\
\hline$\geq 35$ & 05 & 7.7 & 16 & 10.7 & 0.38 \\
\hline
\end{tabular}

BFPCI = Breastfeeding Friendly Primary Care Initiative; $\mathrm{BHC}=$ basic healthcare center.

records from after certification were analyzed. There were no losses because all of the medical records contained the information needed for analysis. It will be observed that the study population exhibited a similar profile at both sampling times, in terms of the sex of the children and the age of the mothers $(p=0.59 ; p=0.38)$, as is illustrated in Table 1.

In Table 2, it can be observed that there was a statistically significant increase in the prevalence of EBF among children under 6 months of age, when the periods before and after implementation of the BFPCI are compared ( $p<0.0001)$. Of particular note is the fact that, for children aged from 4 to 6 months, the prevalence of EBF doubled. Furthermore, there was a reduction in the prevalence of $\mathrm{PBF}$, both among children less than 4 months old and among children aged between
4 and 6 months $(p<0.0001)$. Also of interest was the increase in the prevalence of BF among children more than 6 months old ( $p<0.0001)$, especially among those aged 9 to 12 months (24 vs. $82 \%$ ).

Comparing cause of consultation, before and after accreditation of the $\mathrm{BHC}$, it was observed that in all age groups there was a statistically significant reduction been cancelled patients motivated by some type of disease, after the $\mathrm{BHC}$ had been certificated as being Breastfeeding Friendly, particularly for infants aged more than 4 months (Table 3 ). Of particular prominence in this age group was a reduction by more than half in the number of console patients motivated by diarrhea.

When an analysis was performed of the proportions of health-related outcomes (cause of consultation) for children

Table 2 - Type of feeding by age group of child, before and after BFPCI certification of a BHC in the city of Rio de Janeiro

\begin{tabular}{|c|c|c|c|c|c|c|c|c|c|c|c|c|}
\hline \multirow[b]{3}{*}{ Age group (months) } & \multicolumn{4}{|c|}{ EBF* } & \multicolumn{4}{|c|}{ PBF $^{+}$} & \multicolumn{4}{|c|}{$\mathbf{B F}^{*}$} \\
\hline & \multicolumn{2}{|c|}{ Pre-BFPCI } & \multicolumn{2}{|c|}{ Post-BFPCI } & \multicolumn{2}{|c|}{ Pre-BFPCI } & \multicolumn{2}{|c|}{ Post-BFPCI } & \multicolumn{2}{|c|}{ Pre-BFPCI } & \multicolumn{2}{|c|}{ Post-BFPCI } \\
\hline & $\mathbf{n}$ & $\%$ & $\mathbf{n}$ & $\%$ & $\mathbf{n}$ & $\%$ & $\mathbf{n}$ & $\%$ & $\mathbf{n}$ & $\%$ & $\mathbf{n}$ & $\%$ \\
\hline$<4$ & 82 & 68.0 & 175 & 88.0 & 16 & 13.0 & 6 & 3.0 & 116 & 96.0 & 190 & 95.0 \\
\hline $4-5.9$ & 50 & 41.0 & 163 & 82.0 & 14 & 12.0 & 1 & 1.0 & 104 & 86.0 & 189 & 94.0 \\
\hline $6-8.9$ & - & - & - & - & - & - & - & - & 69 & 57.0 & 172 & 86.0 \\
\hline $9-12$ & - & - & - & - & - & - & - & - & 29 & 24.0 & 164 & 82.0 \\
\hline
\end{tabular}


Table 3 - Frequency of health-related outcomes causing attendance at the neonatal and infant health clinic by child's age, before and after BFPCI certification of a BHC in the city of Rio de Janeiro

Health-related outcome (\%)

\begin{tabular}{|c|c|c|c|c|c|c|c|c|}
\hline \multirow{2}{*}{$\begin{array}{l}\text { Age group } \\
\text { (months) }\end{array}$} & \multicolumn{2}{|c|}{ Asymptomatic* } & \multicolumn{2}{|c|}{ Diarrhea $^{+}$} & \multicolumn{2}{|c|}{$\mathbf{R I}^{*}$} & \multicolumn{2}{|c|}{ Others } \\
\hline & Pre-BFPCI & Post-BFPCI & Pre-BFPCI & Post-BFPCI & Pre-BFPCI & Post-BFPCI & Pre-BFPCI & Post-BFPCI \\
\hline$<4$ & 74.0 & 91.0 & 12.0 & 6.0 & 8.0 & 1.0 & 5.0 & 4.0 \\
\hline $4-5.9$ & 58.0 & 85.0 & 28.0 & 6.0 & 7.0 & 3.0 & 7.0 & 6.0 \\
\hline $6-8.9$ & 44.0 & 72.0 & 41.0 & 12.0 & 6.0 & 5.0 & 9.0 & 11.0 \\
\hline $9-12$ & 41.0 & 72.0 & 38.0 & 11.0 & 11.0 & 6.0 & 11.0 & 12.0 \\
\hline
\end{tabular}

$\mathrm{BFPCI}=$ Breastfeeding Friendly Primary Care Initiative; $\mathrm{BHC}=$ basic healthcare center; $\mathrm{RI}=$ respiratory infections

$* p<0.0001$ in all age groups.

$+p<0.0001$ in all age groups, except those less than 4 months old

$\neq p<0.01$ only for those less than 4 months old.

less than 4 months old, broken down by type of feeding, it was observed that after BFPCI certification there was an increase in routine consultations (asymptomatic) and a reduction in consultations caused by diarrhea. These results were different with statistical significance between children on EBF and those on BF, as can be observed from Figure 1.

\section{Discussion}

This study has demonstrated that positive results were observed after implementation of the BFPCI strategy, both in terms of the increase in the proportion of children being breastfed, particularly those less than 6 months old being

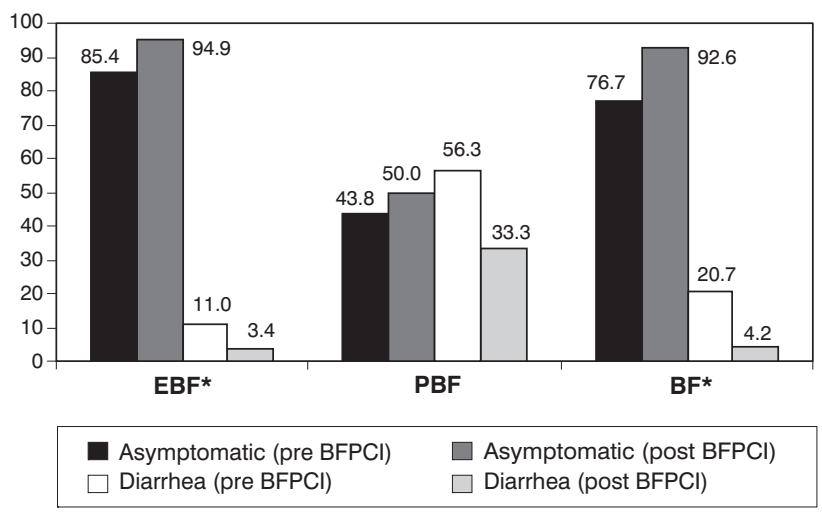

$* p<0.05$

$\mathrm{BF}=$ breastfeeding; $\mathrm{BFPCI}=$ Breastfeeding Friendly Primary Care Initiative; $\mathrm{EBF}=$ exclusive breastfeeding; PBF = predominant breastfeeding.

Figure 1 - Frequency (\%) of health-related outcomes causing consultations at the infant and neonatal clinic, by type of feeding, in children under 4 months old, before and after BFPCI certification of a basic healthcare center in the city of Rio de Janeiro exclusively breastfed, and also in terms of the reduced frequency of consultations caused by common causes of infant morbidity at the BHC studied. These results are relevant to infant health promotion, and also to the prevention of common complaints in child healthcare.

With relation to changes observed in the prevalence of EBF among those less than 4 months old, it should be noted that, even before accreditation, the rate at this BHU (68\%) was already higher than EBF prevalence rates that have been observed in the city of Rio de Janeiro $(31.0 \%)^{10}$ and also than rates observed in municipalities in the state of São Paulo, where the highest prevalence of EBF observed for this age group was $30 \% .{ }^{17}$ Part of the reason for this difference is the heterogeneous nature of the populations studied. Both in the city of Rio de Janeiro and in the municipalities in São Paulo state, the samples were representative of the population of infants aged less than one year who attended for vaccination on national vaccination campaign days and, as such, are composed of differing social and economic strata, which is not the case of the population studied here.

Another contributing reason for this difference may be the adoption of different methodologies for detecting the type of feeding. In the studies in Rio de Janeiro and São Paulo state, a standardized questionnaire was used which had been validated for collecting indicators of type of feeding. In this study, secondary data were used based on records made by health professionals, a methodology which is more susceptible to errors, which would tend to overestimate EBF prevalence rates. Nevertheless, it should be stressed that the majority of health professionals at this $\mathrm{BHC}$, even before all of the procedures and standards of the BFPCI had been implemented, valued correct and regular recording of this information on medical records and had already systematically carried out 
actions to encourage and maintain EBF, such as, for example, a group for welcoming and instructing the pregnant women cared for at this BHC since it was opened. It is therefore plausible that, even if such errors did occur, they were probably not of a great magnitude.

The prevalence of EBF was lower among infants aged from 4 to 6 months, when compared with those less than 4 months old. Some authors have suggested that this difference is probably due to mothers returning to work, since the legal period of maternity leave is 120 days. ${ }^{18}$ Notwithstanding, after the $\mathrm{BHC}$ was accredited as a Breastfeeding Friendly basic healthcare center, the proportion of children aged 4 to 6 months being exclusively breastfed was closer to that observed among those under 4 months than it had been before certification. This is possibly a result of reinforcement of the instruction to comply with step three of the BFPCI (instruct pregnant women and mothers on their rights and the advantages of breastfeeding, promoting exclusive breastfeeding until the baby reaches 6 months and complemented breastfeeding up to 2 years of life or more) and also step 6 (show pregnant women and mothers how to breastfeed and how to maintain lactation even when separated from their children). ${ }^{12}$

A significant reduction in PBF was another relevant result and one which suggests that the BFPCI may be an effective strategy for meeting the international recommendations which encourage exclusive breastfeeding up until 6 months of life. ${ }^{6}$ Venâncio et al. ${ }^{17}$ state that the high prevalence of PBF in Brazil should be seen as a warning signal by health authorities, and that educational actions should be implemented providing mothers with information on the harmful effects of giving non-nutritional liquids to their children during the first few months of life.

With relation to the overall prevalence of BF among children less than 12 months old, it was observed that a greater proportion of children were being breastfed at this BHU after accreditation ( $82 \%$ ) when compared with results for the city of Rio de Janeiro $(68.6 \%)^{10}$ and with national data (37.0\%). ${ }^{8}$ Maintenance of $\mathrm{BF}$ up until the second year of life is part of the BFPCI recommendations ${ }^{12}$ and of Ministry of Health recommendations on feeding children less than 2 years old. ${ }^{19}$ This practice has been identified as a possible protective factor against school age obesity, which is an ever-more common cause of concern in the field of public health, due to the increased risk that such children will become obese adults, in view of the range of morbid conditions that are associated with obesity. ${ }^{20,21}$

Another significant result is related to the change in primary complaints causing consultations at the infant and neonatal clinic. There was an increase in the number of children attending consultations with no complaints, who had been brought to the $\mathrm{BHC}$ for monitoring of child growth and development. Additionally, there was a reduction in the number of consultations where the primary complaint was diarrhea. Data from the Ministry of Health show that in Brazil infectious and contagious diseases are the principal cause linked with infant mortality, when causes connected with perinatal conditions, congenital malformations and anomalies are excluded. 22,23 Diarrhea is not a significant cause of death in infants less than 1 year old in the city of Rio de Janeiro. Nevertheless, there is still a high number of registrations on the program for the treatment of persistent diarrhea, which, in 2003 treated 556 children. ${ }^{24}$ Therefore, actions that result in a reduction in the number of consultations caused by diarrhea should be valued by an integrated child healthcare approach.

Analyzing the profile of complaints causing consultations, according to type of feeding, it was also observed that there were changes for children who were on EBF and BF. It is believed that the reduction in the proportion of consultations motivated by diarrhea may, in part, be the result of an increase in the specificity of diagnosis (thereby reducing the number of false-positive cases), since this is included in a group of subjects dealt with in the training that is part of implementing the BFPCI. It should be noted that the small number of children aged less than 4 months and on PBF, both before and after accreditation of the $\mathrm{BHC}$ ( 16 and six, respectively), may have contributed towards the failure to identify an association between type of feeding and causes of consultation in that age group.

The changes observed in the prevalence rates of type of feeding, always in the direction of meeting the recommendations, indicate the potential of the BFPCI strategy for promotion and maintenance of BF. Studies undertaken in other parts of the country with different methodologies and sample sizes have also observed positive effects on the proportion of EBF (of similar or greater magnitude), when the locus of actions was the $\mathrm{BHC}$, prioritizing investment in training and raising the awareness of health professionals. ${ }^{25-28}$ The potential of this strategy is due to its being based on actions considered effective, the fact that it is implemented by the $\mathrm{BHC}$ and by its role in making the team reflect on the practices adopted in caring for pregnant women, mothers and babies, and their families.

Nevertheless, certain limitations of a methodological nature should be pointed out. Since the study employed secondary sources of data, few variables could be used to compare the pre- and post-implementation groups (sex of child and age of mother). It is not therefore known whether the distribution of potential confounding variables was similar between the two groups, in particular variables related to perinatal care (type of delivery, type of hospital - whether public or private and whether affiliated to the Baby Friendly Hospital Initiative or not). It is reasonable to suppose that other characteristics of the children (birth weight) and the family (presence of partner at home, educational level, income and living conditions) were similar among the two study populations. The fact that variables which may have contributed to changes 
in prevalence rates of the outcomes studied were not recorded does not allow us to claim that the results were exclusively due to implementation of the BFPCI. It should also be pointed out that extrapolation of the results observed here to other localities merits caution, since it was carried out in a specific location in the city of Rio de Janeiro. Nevertheless, despite the limitations described, the changes in the outcomes investigated after BFPCI certification of the BHC are worthy of note.

It was concluded that the BFPCI is a strategy that contributes to increasing the prevalence rates of EBF and $\mathrm{BF}$ and of reducing both $\mathrm{PBF}$ and the proportion of consultations primarily caused by diarrhea, in infants aged less than one year seen at this BHC belonging to the municipal healthcare system of Rio de Janeiro. Our experience of managing and implementing the BFPCI within primary care (conventional healthcare centers and family healthcare teams) in this city has shown us that this is a tool that transforms working processes and the perceptions of health professionals, thereby having a significant impact on the adoption and maintenance of EBF and complemented BF up to 2 years of life or more.

\section{Acknowledgements}

The authors would like to thank the management and the entire team of health professionals at the CMS Harvey Ribeiro de Souza Filho for their support of this study and Dr. Maria Inês de Oliveira for her extremely detailed proofreading and the extremely important suggestions she made on a preliminary version of this manuscript.

\section{References}

1. Goldberg HI, Rodrigues W, Thomé AM, Janowitz B, Morris L. Infant Mortality and breastfeeding in North-Eastern Brazil. Popul Stud (Camb). 1984;38:105-15.

2. Habicht JP, DaVanzo J, Butz WP. Does breastfeeding really save lives, or are apparent benefits due to biases? Am J Epidemiol. $1986 ; 123: 279-90$.

3. Monteiro CA, Rea M, Victoria C. Can infant mortality be reduced by promoting breastfeeding? Evidence from São Paulo City. Health Policy Plan. 1990;5:23-9.

4. Newman J. How breast milk protects newborns. Sci Am. 1995; 4:76-9.

5. Ravelli AC, van der Meulen JH, Osmond C, Barker DJ, Bleker OP. Infant feeding and adult glucose tolerance, lipid profile, blood pressure, and obesity. Arch Dis Child. 2000;82:248-52.

6. World Health Organization. The optimal duration of exclusive breastfeeding. http://www.who.int/nutrition/publications/ optimal_duration_of_exc_bfeeding_report_eng.pdf. Access: $12 / 09 / 2007$.

7. Sociedade Civil Bem-Estar Familiar no Brasil. Pesquisa nacional sobre demografia e saúde 1996. $2^{a}$ ed. Rio de Janeiro, RJ: BEMFAM; 1999.

8. Brasil. Ministério da Saúde. Pesquisa de prevalência do aleitamento materno nas capitais e no Distrito Federal. Brasília: Ministério da Saúde; 2001.
9. Ferreira L, Parada CM, Carvalhaes MA. Tendência do aleitamento materno em município da região centro-sul do estado de São Paulo: 1995-1999-2004. Rev Nutr. 2007;20:265-73.

10. Castro IR, Silva MA, Cardoso LO, Damião JJ, Rito RV, Engstrom EM. Evolução do Aleitamento Materno no Município do Rio de Janeiro no período de 1996 a 2003. Rio Estudos. 2004;136. http://www.armazemdedados.rio.rj.gov.br/arquivos/22_ evolução\%20do\%20aleitamento\%20materno\%20de\%20 1996\%20a\%202003.PDF. Access: 05/02/2007.

11. Oliveira MI, Camacho LA, Souza IE. Promoção, proteção e apoio à amamentação na atenção primária à saúde no Estado do Rio de Janeiro, Brasil: uma política de saúde pública baseada em evidência. Cad Saude Publica. 2005;21:1901-10.

12. Secretaria de Estado de Saúde do Rio de Janeiro. Resolução SES No 2.673 de 02 de março de 2005. Rio de Janeiro: Secretaria de Estado de Saúde do Rio de Janeiro; 2005. http:// www.saude.rj.gov.br/publicacoes/Res2673.shtml. Access: 04/ $10 / 2007$.

13. de Oliveira MI, Camacho LA, Tedstone AE. Extending breastfeeding duration through primary care: a systematic review of prenatal and postnatal interventions. J Hum Lact. 2001; 17:326-43.

14. World Health Organization (WHO). United Nations Children's Fund. Indicators for assessing health facility practices that affect brestfeeding. Report of the joint WHO/UNICEF informal interagency meeting. Geneve: WHO/UNICEF; 2001.

15. Organização Mundial de Saúde. Classificação Internacional de Doenças (CID 10). São Paulo: OPAS; 1995.

16. Dean A, Dean J, Burton A, Dicker R. Epi-info, version 6.04: word processing, data base and statistics program for epidemiology on microcomputers. Atlanta, GA: CDC; 1990.

17. Venâncio SI, Escuder MM, Kitoko P, Rea MF, Monteiro CA. Freqüência e determinantes do aleitamento materno em municípios do Estado de São Paulo. Rev Saude Publica. 2002; 36:313-8.

18. Vannuchi MT, Thomson Z, Escuder MM, Tacla MT, Vezozzo KM, de Castro LM, et al. Perfil do aleitamento materno em menores de um ano no Município de Londrina, Paraná. Rev Bras Saude Mater Infant. 2005; 5:155-62.

19. Brasil. Ministério da Saúde. Secretaria de Política de Saúde. Organização Pan Americana de Saúde. Guia alimentar para crianças menores de 2 anos. Brasília: Ministério da Saúde; 2002.

20. Siqueira RS, Monteiro CA. Amamentação na infância e obesidade na idade escolar em famílias de alto nível socioeconômico. Rev Saude Publica. 2007;41:5-12.

21. Balaban G, Silva GA. Efeito protetor do aleitamento materno contra a obesidade infantil. J Pediatr (Rio J). 2004;80:7-16.

22. Brasil. Ministério da Saúde. Evolução da mortalidade infantil no Brasil. http://portal.saude.gov.br/saude. Access: 16/09/2007.

23. Victora $C$, Barros FC. A questão da sobrevivência infantil no mundo e sua relevância para as Américas. Cadernos ESP - Escola Saúde Pública Ceará. 2005;1:1-10.

24. Rocha M. PRODIAPE: Práticas Pediátricas. São Paulo: Atheneu; 2006.

25. Narchi NZ, Fernandes RA, Gomes MM, Queiroz ML, Higasa DN. Análise da efetividade de um programa de incentivo ao aleitamento materno exclusivo em comunidade carente na cidade de São Paulo. Rev Bras Saude Mater Infant. 2005;5: 87-92. 
26. Barros FC, Semer TC, Tonioli Filho S, Victora CG. Avaliação do impacto de Centros de Lactação sobre padrões de amamentação, morbidade e situação nutricional: um estudo de coorte. Rev Bras Epidemiol. 2002;5:5-14.

27. Faleiros JJ, Kalil G, Casarin DP, Laque PA Jr, Santos IS. Avaliação do impacto de um programa de puericultura na promoção da amamentação exclusiva. Cad Saude Publica. 2005;21:482-9.

28. Lana AP, Lamounier JA, César CC. Impacto de um programa para promoção da amamentação em um centro de saúde. J Pediatr (Rio J). 2004;80:235-40.
Correspondence:

Letícia de Oliveira Cardoso

Escola Nacional de Saúde Pública

Departamento de Epidemiologia e Métodos Quantitativos em Saúde

Rua Leopoldo Bulhões, 1480/813, Manguinhos

CEP 21041-210 - Rio de Janeiro, RJ - Brazil

Tel.: +55 (21) 2598.2619, +55 (21) 2475.0515, +55 (21)

8148.5670

Fax: +55 (21) 2270.6772

E-mail: leticiaocar@ensp.fiocruz.br 